\title{
Efficacy of Skin Traction in Elderly Neck of Femur Fractures for Pre Operative Pain Relief.
}

\author{
Dr. Siddharth Munireddy ${ }^{1}$; Dr. Swaroop Chandra ${ }^{2}$; Dr. L. Senthil ${ }^{3}$ \\ ${ }^{1,2,3}$ Department Of Orthopaedics, Sri Ramachandra University, Chennai, India.
}

\begin{abstract}
AIM: To Compare The Pre Operative Role And Efficacy Of Skin Traction In The Pain Management In Neck Of Femur Fractures Among Elderly Patients.
\end{abstract}

\section{Introduction}

Fractures of the neck of femur are seen mostly among the elderly, often result from low-energy falls, and are commonly associated with osteoporosis. Neck of femur fractures comprise $20 \%$ of the operative workload of an orthopaedic trauma unit. ${ }^{(1)}$

Intra-capsular femoral neck fractures account for $50 \%$ of all hip fractures. The lifetime risk of sustaining a hip fracture is high and lies within the range of $40 \%$ to $50 \%$ in women and $13 \%$ to $22 \%$ in men. Life expectancy is increasing worldwide, and these demographic changes can be expected to cause the number of hip fractures occurring worldwide to increase from 1.66 million in 1990 to 6.26 million in 2050. ${ }^{(2)}$

A study by Billsten $\mathrm{Et}^{\mathrm{Al}}{ }^{(3)}$ in Sweden confirms that the use of pre-operative skin traction is still common, though literature questions the usefulness of this ${ }^{(4)(5)(6)}$.

In intra-capsular fractures of the neck of femur, advantages of traction such as the possibility of a reduction of circulatory complications have been proposed. For example, traction reduces the tamponade effect within the joint ${ }^{(9)}$ and may secondarily aid in fracture stability at the interface and decrease the deformity at the fracture site. Either of these will reduce the risk of damage to the blood supply to the femoral head via the retinacular vessels. It has been postulated that these two effects might lead to a decreased incidence of nonunion or avascular necrosis of head of femur; however, supportive evidence is lacking. Skin traction has potential disadvantages. It makes nursing the patient tedious; for example, lifting the patient onto a bedpan or in pressure area care prior to surgery. Other adverse effects are skin damage by mechanical shearing, ischemia due to tight bandages or adhesive strapping allergy. On the contrary, a study by Stromqvist B Et $\mathrm{Al}^{(10)}$ has suggested that the position of slight flexion, abduction and external rotation of the hip achieved the lowest intracapsular pressure. This is contrary to the position used for traction; the hip in neutral, instead, may thereby increase intra-capsular pressure ${ }^{(11)}$.

\section{Materials \& Methods}

100 elderly patients (age > $60 \mathrm{yrs}$ ) with neck of femur fractures who were admitted in Sri Ramachandra University from April 2012 to April 2016 were recruited in the study. Patients were randomised into two study groups. Those in the First group were not given traction, instead, a pillow was placed under the injured leg. While those in the second group were put on foam skin traction with a weight of $6 \%$ of their total body weight. Young patients, patients with peripheral vascular disease or skin problems and those with a mini mental state examination of less than 24 were excluded. Pain scoring using a visual analogue scale was done twice a day. Drug dispensation was performed three times a day. The following data was collected by an orthopaedic resident: age, sex, mental state score, waiting interval until operation, type of fracture and analgesic requirements (choice of analgesia was based on Departmental protocol).

\section{Results}

We analysed the results of 100 patients of which there were a total of 37 men and 63 women and the average age was 67 years. Most common cause of injury was skid and fall. 14 patients had gardens type 1 fracture. 31 patients had gardens type 2 fracture. 28 patients had gardens type 3 fracture and 27 patients had type 4 fracture. The average waiting time for surgery was found to be 4.73 days with an average of 4.84 and 4.63 days for patients with traction and without traction respectively. The two groups were compared with respect to age, gender and distribution of type of fracture. 


\begin{tabular}{|l|l|l|l|l|l|l|l|}
\hline & \multicolumn{5}{|l|}{ Gender } & \multicolumn{3}{l|}{ Type of fracture - Gardens classification } & $\begin{array}{l}\text { Waiting interval } \\
\text { until operation }\end{array}$ \\
\hline & & & Type 1 & Type 2 & Type 3 & Type 4 & \\
\hline $\begin{array}{l}\text { Traction (no- } \\
\text { 50) }\end{array}$ & M=16 & F- 34 & 8 & 12 & 18 & 12 & Average - 4.84 \\
\hline $\begin{array}{l}\text { No traction } \\
\text { (no-50) }\end{array}$ & M-21 & $(68 \%)$ & $(16 \%)$ & $(24 \%)$ & $(36 \%)$ & $(24 \%)$ & \\
\hline
\end{tabular}

\section{Preoperative pain Graph}



\section{Average daily oral analgesic requirements}

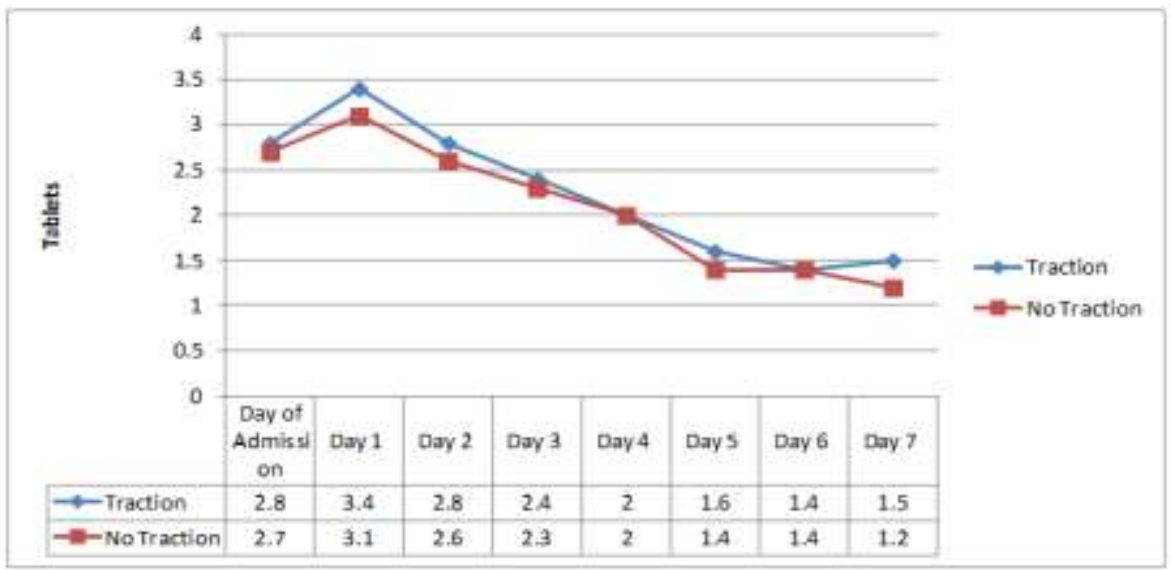

The mean pain score on the day of admission was 1.45 for patients with skin traction and 1.54 among those without skin traction. On day 1, the pain scores increased to $2.85 \& 2.7$ for those with skin traction and those without skin traction respectively. The peak pain score was found to be on the end of day one for both groups after which we saw a decline in the pain scores of both groups. The arithmetic means and correlation coefficient were calculated and the arithmetic mean of pain scores with and without foam skin does not significantly differ and there exists a nearly perfect positive correlation between the two groups. this indicates that there was no impact on the pain scores with foam skin traction. The difference in the arithmetic mean for analgesic intake for both the groups is negligible, and indicates that traction has no impact on analgesic intake. The $\mathrm{p}$ value for difference in pain score and analgesic requirements was not less than 0.05 and hence statistically insignificant. 


\section{Discussion}

The use of skin traction in elderly neck of femur fractures is a common practice. ${ }^{(3)}$ In our hospital too, we do use skin traction though many articles suggested the ineffective nature in pain relief. ${ }^{(4)(5)(6)(12)}$ Geriatric neck of femur patients often have concurrent medical co morbidities and the treatment modalities taken to resolve these risks among patients tends to delay the surgery from the time of obtaining a fracture. Therefore pain control is of importance during the pre operative period. Many publications state that hip surgeries were done within 2-3 days and Rosen et al ${ }^{(13)}$ states within 24 hours. However, in our country, most orthopaedic units are unable to achieve this time frame. Under these circumstances, we believed that patients who had to wait longer for their surgeries, needed skin traction. Our study has proved it not to be so. It could also be possible that the natural course of the pain is that it is worst during the first few days and then adaptation is rapid, and hence not affected by longer waiting periods.

The pain among both groups of patients was found to be maximal on the end of day one. The pain score on the day of admission was lesser than that seen on day 1 after admission. The analgesic requirements of the group with skin traction was marginally higher than that of the group without skin traction.

Hence, skin traction is not beneficial in the pain management in elderly neck of femur fracture patients and there is no scientific data supporting its effectiveness. Thus concluding that foam skin traction used for pain relief in elderly neck of femur patients is ineffective.

\section{Conclusion}

In our study, skin traction did not result in significant pain relief in elderly neck of femur fracture patients. Patients with pillow elevation of the lower limb had better pain relief.

\section{References}

[1]. Singer BR, McLauchlan GJ, Robinson CM, et al. epidemiology of fractures in 15,000 adults: The influence of age and gender. J bone joint surgery Br. 1998;80(2):243-248.

[2]. Dennison E, Mohamed MA, Cooper C. Epidemiology of osteoporosis. Rheum Dis Clin North Am. 2006;32(4):617-629.

[3]. Billsten M, Besjakov J, Hyddmark U, Johnell O, Sernbo I (1996) Enquiry in Sweden on the use of traction preoperatively in patients with hip fracture and a radiological study on the effect of the traction on ten displaced cervical hip fractures. ActaOrthop Scand [Suppl] 270:35 (abstract)

[4]. Anderson GH, Harper WM, Connolly CD, Badham J, Goodrich N, Gregg PJ (1993) Preoperative skin traction for fractures of the proximal femur. A randomised prospective trial. J Bone Joint Surg [Br] 75:794-796

[5]. Finsen V, Borset M, Buvik GE, Hauke I (1992) Preoperative traction in patients with hip fractures. Injury 23:242-244

[6]. Needoff M, Radford P, Langstaff R (1993) Preoperative traction for hip fractures in the elderly: a clinical trial. Injury 24:317-318

[7]. Yip DHK, Chan CF, Chiu PKY, et al. Why are we still using pre-operative skin traction for hip fractures? Int Orthop. 2002; 26:3614.

[8]. Billsten M, Besjakov J, Hyddmark U, et al. Enquiry in Sweden on the use of traction preoperatively in patients with hip fracture and a radiological study on the effect of the traction on ten displaced cervical hip fractures. Acta Orthop Scand. 1996;67(Suppl 270):35.

[9]. Maruenda JI, Barrios C, Llombart R, Gomar F (1992) Intracapsular pressure and femoral head bone circulation in femoral neck fractures. Acta Orthop Scand [Suppl] 248:83 (abstract)

[10]. Stromqvist B, Nilsson LT, Egund N, Thorngren K-G, Wingstrand H (1988) Intracapsular pressures in undisplaced fractures of the femoral neck. J Bone Joint Surg [Br] 70:192-194

[11]. Svalastoga E, Kiaer T, Jensen PE (1989) The effect of intracapsular pressure and extension of the hip on oxygenation of the juvenile femoral epiphysis. J Bone Joint Surg [Br] 71:222-226

[12]. Daniel Kwok Hing Yip, Chi Fat Chan, Peter K.Y.Chiu, Jimmy W.K. Wong, James K.F. Kong (2002) Why are we still using pre operative skin traction for hip fractures?. International Orthopaedics (SICOT) 26:361-364

[13]. Rosen JE, Chen FS, Hiebert R, Koval KJ (2001) Efficacy of pre-operative skin traction in hip fracture patients: a prospective randomised study. J Orthop Trauma 15:81-85 